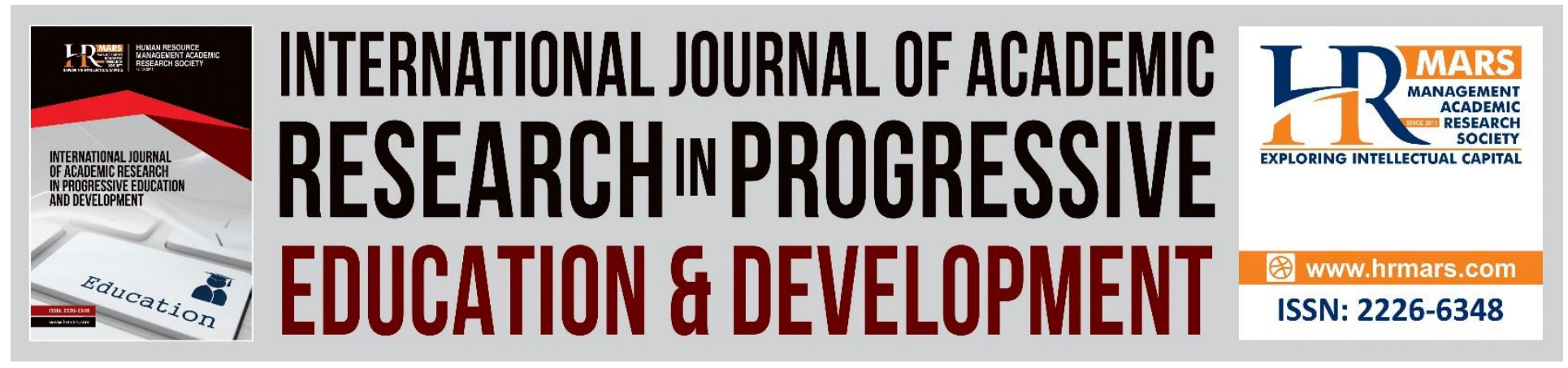

\title{
A Conceptual Framework for Early Intervention Guideline in Improving the Social Skills of Autism Spectrum Disorder Children
}

\section{Maha Khaleel Al Jirjawy, Noor Aini Ahmad, Yoong Soo May}

To Link this Article: http://dx.doi.org/10.6007/IJARPED/v10-i1/9041

DOI:10.6007/IJARPED/v10-i1/9041

Received: 03 December 2020, Revised: 01 January 2021, Accepted: 17 January 2021

Published Online: 30 January 2021

In-Text Citation: (Jirjawy et al., 2021)

To Cite this Article: Jirjawy, M. K. Al, Ahmad, N. A., \& May, Y. S. (2021). A Conceptual Framework for Early Intervention Guideline in Improving the Social Skills of Autism Spectrum Disorder Children. International Journal of Academic Research in Progressive Education and Development, 10(1), 331-338.

Copyright: (C) 2021 The Author(s)

Published by Human Resource Management Academic Research Society (www.hrmars.com)

This article is published under the Creative Commons Attribution (CC BY 4.0) license. Anyone may reproduce, distribute, translate and create derivative works of this article (for both commercial and non-commercial purposes), subject to full attribution to the original publication and authors. The full terms of this license may be seen at: http://creativecommons.org/licences/by/4.0/legalcode

Vol. 10(1) 2021, Pg. 331 - 338

http://hrmars.com/index.php/pages/detail/IJARPED JOURNAL HOMEPAGE

Full Terms \& Conditions of access and use can be found at http://hrmars.com/index.php/pages/detail/publication-ethics 


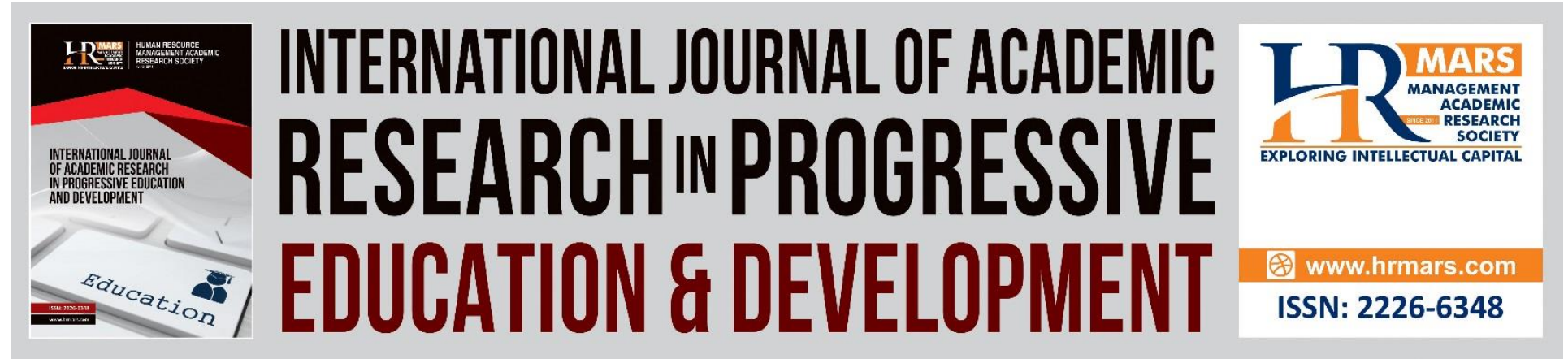

\title{
A Conceptual Framework for Early Intervention Guideline in Improving the Social Skills of Autism Spectrum Disorder Children
}

\author{
Maha Khaleel Al Jirjawy \\ Department of Special Education, Faculty of Human Development Universiti Pendidikan Sultan \\ Idris, Malaysia. \\ Noor Aini Ahmad \\ Department of Special Education, Faculty of Human Development Universiti Pendidikan Sultan \\ Idris, Malaysia. \\ Yoong Soo May \\ Department of Special Education, Faculty of Human Development Universiti Pendidikan Sultan \\ Idris, Malaysia.
}

\begin{abstract}
The purpose of this study is to develop an early intervention guideline for autism spectrum disorder (ASD) children in Jordan. The objectives of this early intervention guideline are to improve the social skills of children with autism spectrum disorder and to train parents on the most important methods used in training their ASD children in communication. This study is a quantitative study which employs quasi-experimental design. The sample will be divided into one control group and one experimental group. The researchers will use the questionnaire as a tool to measure the families' needs and identify children's deficiency in social behaviour and communication skills. This study consists of three stages. During the first stage, the questionnaires in Google form will be distributed to mothers of ASD children by random sampling. The data will be analyzed and the elements in the questionnaire will be validated. During the second stage, guidelines for the experimental group will be provided. During the third stage, the researcher will analyze the results and determine the effectiveness of early intervention guideline. The implication of this study is this early intervention guideline can be practiced among the families of ASD children in order to improve the social skills of their children. Keywords: Early Intervention, Guideline, Autism Spectrum Disorder, Social Skills, Communication.
\end{abstract}




\section{Introduction}

Autism spectrum disorder (ASD) is defined by observed impairments in social and communicative interaction and excessive stereotyped patterns of behaviour (Mikkelsen et al., 2018). As diagnostic criteria shows, social communication difficulties are one of the core features of ASD. The persistent deficits in ASD have been viewed since the current diagnostic criterion of ASD combines social interaction and communication (Loukusa et al., 2018). Considerable research exists on interventions to train parents to manage problem behaviour in ASD children. Parenting interventions typically aim to increase parental knowledge, skills and confidence in managing problem behaviour (O'Nions et al., 2018).

Special education is an education specially designs for the pupils who have special educational need. Teachers and parents should always make sure that the children are receiving the proper education as they are required to (Yoong \& Ahmad, 2020). Although it is challenging experience to deal with children with special education, however there are alternative ways that are helpful for these children (Ahmad, 2018). Among these alternative ways, early intervention guideline seems to be one of the best ways to deal with ASD children.

Thus, the purpose of this study is to develop an early intervention guideline to improve the social behaviour among ASD children. Three objectives of this study are: (1) to determine the parents' needs to develop an early intervention guideline for ASD children in Jordan; (2) to develop an early intervention guideline to improve the social behaviour among ASD children in Jordan; and (3) to measure the effectiveness of the early intervention guideline in improving the social behaviour among ASD children in Jordan.

\section{Literature Review}

In this section, four literature reviews will be discussed, namely: early intervention, autism spectrum disorder, social skills, and communication skills.

\section{Early Intervention}

Education for special educational needs children should be given priority. This is to ensure every child has the chance to learn according to their needs and abilities (Yahya, Ahmad \& Yoong, 2019). The knowledge about intervention is very crucial among teachers and parents in order to reduce and minimizing the negative impact of the disability in their daily lives (Yoong, 2020). Most early intervention programs are designed for preschool-aged children, although they may include younger children in their programs as well. It is only more recently that we have been able to identify children with autism as young as two years of age. There are a few programs that are specifically designed for children between birth and three years of age (Corsello, 2005).

Intervening upon early sensory responsiveness may improve the social outcomes in children with ASD. This theory is intuitively appealing, given the precedence and possible foundational nature of early sensory development relative to the emergence of higher-level social and communication abilities (Baranek et al., 2018). Developmental intervention procedures emphasize child-initiated social interaction, which provide a context for learning, and focus on improving social orienting and social communicative abilities (Houghton, Schuchard, Lewis \& Thompson, 2013). 
Thus, early intervention has effective effects in improving the language understanding of the child and reduces the severity of the characteristics of ASD child, and the stress of parents and increase the confidence of parents. Early intervention also improves the quality of life and helps to regulate the emotional and increases response to children's autistic behaviour and lowers the level of stress and depression for the family. Early intervention increases the self-sufficiency of parents and increases the communication skills of ASD children to reduce inappropriate behaviours, which will then helps the child to integrate and be accepted in the community.

\section{Autism Spectrum Disorder}

Autism Spectrum Disorder (ASD) is a developmental disorder that begins in very early childhood and affects individuals throughout their lives, impacting reciprocal social behavior, and thus relationships (Cascio, Moore \& McGlone, 2019). Autism adolescences have a problem on how to regulate their emotion. They have difficulty to express their emotion in a right way due to difficulties in interpreting others feeling and have less experience in feeling any emotion like a typical person. Besides, they easily get stress and anxious as they are lacking of social skills (Paulraj, Alwi \& Vetrayan, 2016).

Despite the importance of the ability to parse social interactions in building the knowledge of others and the relationships between them, relatively a few studies have investigated the brain's response to observed social interactions between multiple actors. Instead, the bulk of the current social vision literature has focused on the perception and appraisal of individual agents (Walbrin, Downing \& Koldewyn, 2018). Thus, ASD children have difficulties in socialization. They do not know how to express their emotion in a proper way like a typical person. The deficits in communication skills make them to have difficulty in accomplishing social interactive goals. So, parents should play a role and concern about their ASD children.

\section{Social Skills}

Social motivation, behavioral inhibition and volition to initiate overtures can influence the number, frequency and range of social situations individuals engage in (Spain, Sin, Linder, McMahon \& Happe, 2018). Communicative environments that are over-stimulating, leading to less practice with social scenarios and ultimately resulting in a breakdown of successful social interaction (Thye et al., 2018). The core symptoms are persistent deficits in social communication and social interaction across multiple contexts and restricted, repetitive patterns of behavior, interests or activities. The social disability is multifaceted with deficits in social emotional reciprocity and non-verbal communication, and deficits in developing, understanding and maintaining relationships in social (Vuijk \& Arntz, 2017).

Thus, social interaction is crucial among all of us. Since ASD children are having deficits in this skill, so we have to play a role in helping them to build their social skills. This social ability will enhance their learning, and maintain a relationship between ASD and the community around them. Communication skills include non-verbal and verbal language skills. They are critical in learning and developing social bonds, implement evidence based practices to improve the nonverbal communication skills of ASD children. Positive non-verbal communications are kissing and 
hugging, whereas negative non-verbal communications such as frowning can send the wrong message to children (Alokla, 2018). Research has shown that play may help develop cognitive, social, linguistic, and emotional development. This resource is based on evidence-based practices and strategies that can be used to teach the ASD child with a diagnosis of how to play. This diagnosis teaches them the basis on how to play independently and ultimately socialize with their peers (Howcroft et al, 2012). PECS is very simple and clear and contains an object represented as images in the cards used to express the needs of ASD. The system was found to be very effective in training language basics and helping ASD children in learning (Soomro \& Soomro, 2018).

Hence, non-verbal communication skills are proved to be critical for ASD children in developing their functional communication skills. Deficit in communication skills has become one of the core symptoms for ASD children. These children have a slow developmental progress to learn speaking. They may even unable to talk at all. Some of them may learn to produce words and sentences but have difficulty in using them effectively. So, adults around the ASD children should give them support in helping them to develop their communication skills effectively.

\section{Conceptual Framework}

Figure 1 shows the conceptual framework in this study. This figure illustrate the methods used in this study reinforce modeling observation and imitation. Play is an active role in behavior acquisition and social response for ASD children, especially in early intervention and family guidance. The importance of the early stages of the child's life in acquiring, improving social behavior, communication skills, expression of feelings and has an effective impact in integration with society. The guidance and support of the family has the effect in improving the behavior of their children which facilitates the process of integrating them into society and relieves the burden of the psychological and physical families so that we seek to reach the highest levels of self-sufficiency for the child and the family.

The researcher will identify the needs of autistic children's families through a questionnaire that demonstrates the most important social skills that help their autistic children to be accepted in the society. Developing a clear understanding of the behavioral manifestations characteristic of ASD is an important area of scientific research as current diagnosis of ASD relies completely on behavioural observations (Martins et al., 2015).

Albert Bandura's Social Cognitivism had a significant influence on the psychology in the schools. Just as Piaget and Vygotsky, Bandura is a cognitive psychologist because his theory focuses on motivation and self-regulatory mechanisms rather than just environmental factors. However, Bandura's psychological work builds a bridge between both behaviorist and cognitive theories by encompassing attention memory and motivation. Furthermore, his theory assumes that people learn by observing and imitating other people's behaviors and reactions. As Bandura's theory becomes more popular, it is evident that his theory can also be described as the common sense theory and is grasping many educators' and institutions' attention. The children are in continues interaction with their parents, teachers, relatives and peers in the period of socialization (Yuksel \& Canel, 2012).

The learner has the ability to influence his own learning in new situations by controlling the environment around them. Learners observe the behaviors of others in order to start the learning 


\section{INTERNATIONAL JOURNAL OF ACADEMIC RESEARCH IN PROGRESSIVE EDUCATION AND DEVELOPMENT}

Vol. 10, No. 1, 2021, E-ISSN: 2226-6348 @ 2021 HRMARS

process. After observing the behavior of others, they absorb and mimic the behavior, especially if the observation experiences are positive or include rewards related to the observed behavior. According to Bandura, imitation involves the actual reproduction of observed motor activities. In behavior modeling, the learner takes everything positive about observed and imitated behavior, and started acting, making it easy to design and use role-playing and simulation tools for many different exercises topics (Smith \& Berge, 2009).

Behavioral curricula emphasize the importance of operational behaviors and objectives. All targeted behaviors should be clearly defined to the objectives. The behavior should be described in the observable ways (Charlop, Lang \& Rispoli, 2018).

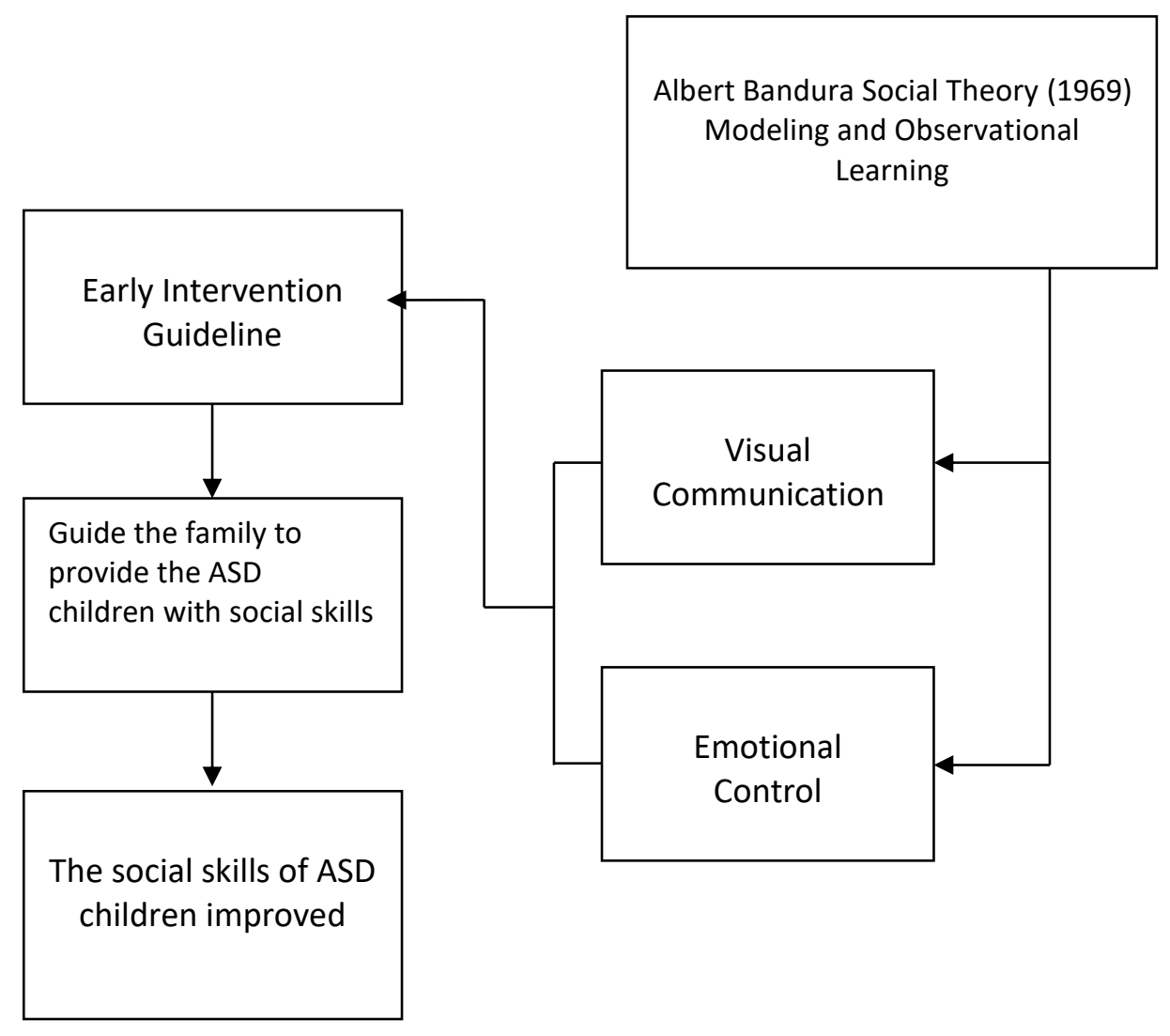

Figure 1 Conceptual Framework

\section{Discussion and Conclusion}

The current study aimed to improve the social skill of the ASD child through early intervention, guidance and raise the awareness of their family on how to improve their social skills through training the child in his natural environment and familiar places. This will lead to the emergence of a marked improvement in the level of social skills. This is in line with Ahmad and Yoong (2018), these children should receive quality service in special education. They should be given space and opportunity to achieve their full potentials. 
Vol. 10, No. 1, 2021, E-ISSN: 2226-6348 @ 2021 HRMARS

To improve the social skill of children with ASD, early intervention and guidance for the family will be applied. The researcher had designed a conceptual framework. This framework is divided into two phases. The first stage is training in visual communication and increasing the attention span of the child. The second stage includes training in expression of feelings and social skills.

In conclusion, this early intervention guideline is very important in improving the parent-children interactions. It also leads the parents to play their role in their ASD children's development. Hence, the families of ASD children can practice this early intervention guideline in order to improve the social skills among their children.

\section{Corresponding Author}

Noor Aini Ahmad

Department of Special Education, Faculty of Human Development Universiti Pendidikan Sultan Idris, Malaysia.

Email: noor.aini@fpm.upsi.edu.my

\section{References}

Ahmad, N. A. (2018). Inclusive education: better and for the best. International Journal of Academic Research in Progressive Education and Development, 7(3), 557-568.

Ahmad, N. A., \& Yoong, S. M. (2018). Challenges in preparing teachers for inclusive education and its impact to students with learning disabilities. International Journal of Academic Research in Progressive Education and Development, 7(3), 569-581.

Alokla, S. A. T. (2018). Non-verbal Communication Skills of Children with Autism Spectrum Disorder. (Master of Arts), California State University, Electronic Theses, Projects, and Dissertations.

Cascio, C. J., Moore, D., \& McGlone, F. (2019). Social touch and human development. Developmental Cognitive Neuroscience, 35, 5-11.

Charlop, M. H., Lang, R., \& Rispoli, M. (2018). More than just fun and games: definition development, and intervention or children's play and social skills. In Charlop, M.H., Lang, R., Rispoli, M. (Eds.). Play and Social Skills for Children with Autism Spectrum Disorder (pp. 1-16). New York: Springer.

Corsello, C. M. (2005). Early intervention in autism. Infants \& Young Children, 18(2), 74-85.

Erturk, B. (2020). Experimental Examination of the Effects of Parent-implemented Select Intervention on Social-emotional Development of Infants and Toddlers. (PhD Dissertation). United States: University of Oregon.

Houghton, K., Schuchard, J., Lewis, C., \& Thompson, C. K. (2013). Promoting child-initiated socialcommunication in children with autism: Son-Rise Program intervention effects. Journal of Communication Disorders, 46(5-6), 495-506.

Loukousa, S., Makinen, L., Kuusikko-Gauffin, S., Ebeling, H., \& Leinonen, E. (2018). Assessing social-pragmatic inferencing skills in children with autism spectrum disorder. Journal of Communication Disorders, 73, 91-105. 
INTERNATIONAL JOURNAL OF ACADEMIC RESEARCH IN PROGRESSIVE EDUCATION AND

DEVELOPMENT

Vol. 10, No. 1, 2021, E-ISSN: 2226-6348 @ 2021 HRMARS

Martins, R., Bonito, I., Andrade, A., Albuquerque, C., \& Chaves, C. (2015). The impact of the diagnosis of autism in parents of children. Procedia-Social and Behavioral Sciences, 171, 121-125.

Mikkelsen, M., Wodka, E. L., Mostofsky, S. H., \& Puts, N. A. (2018). Autism spectrum disorder in the scope of tactile processing. Developmental Cognitive Neuroscience, 29, 140-150.

O'Nions, E., Happe, F., Evers, K., Boonen, H., \& Noens, I., (2018). How do parents manage irritabiliy, challenging behavior, non-compliance and anxiety in children with autism spectrum disorders? A meta-synthesis. Journal of Autism and Developmental Disorders, 48(4), 1272-1286.

Paulraj, S. J. P. V., Alwi, N. A. B., \& Vetrayan, J. (2016). Emotional behavior among autism and typically developing children in Malaysia. Procedia-Social and Behavioral Sciences, 222, 2835.

Smith, M., \& Berge, Z. L. (2009). Social learning theory in Second Life. MERLOT Journal of Online Learning and Teaching, 5(2), 439-445.

Soomro, N., \& Soomro, S. (2018). Autism children's app using PECS. Annals of Emerging Technologies in Computing (AETiC), 2(1), 7-16.

Spain, D., Sin, J., Linder, K. B., McMahon, J., \& Happe, F. (2018). Social anxiety in autism spectrum disorder: a systematic review. Research in Autism Spectrum Disorders, 52, 51-68.

Thye, M. D., Bednarz, H. M., Herringshaw, A. J., Sartin, E. B., \& Kana, R. K. (2018). The impact of atypical sensory processing on social impairments in autism spectrum disorder. Developmental Cognitive Neuroscience, 29, 151-167.

Vuijk, R., \& Arntz, A. (2017). Schema therapy as treatment for adults with autism spectrum disorder and comorbid personality disorder: protocol of a multiple-baseline case series study testing cognitive-behavioral and experiential interventions. Contemporary Clinical Trials Communications, 5, 80-85.

Walbrin, J., Downing, P., \& Koldewyn, K. (2018). Neural responses to visually observed social interactions. Neuropsychologia, 112, 31-39.

Yahya, A. Y., Ahmad, N. A., \& Yoong, S. M. (2019). A new dimensional in teaching non-verbal students with learning disabilities. International Journal of Academic Research in Business and Social Sciences, 8(12), 2099-2108.

Yoong, S. M. (2020). An introduction: what do you know about dyscalculia? In Habidin, N.F., Yong, S.Y.O., Chik, T.W.T. \& Muhamad, U.A. (Eds.). The Revolution in Social Research and Edcuation (pp. 82-88), Tanjung Malim: Kaizentrenovation.

Yoong, S. M., \& Ahmad, N. A. (2020). The needs and significance to design and develop a dyscalculia checklist. Malaysian Science and Mathematics Education Journal, 10(2), 8-14.

Yuksel, M., \& Canel, A. N. (2012). The analysis of social competency and anti-social behaviors of children aged between 4 and 5 from the perspective of marital satisfaction and some other variables. Procedia-Social and Behavioral Sciences, 46, 4973-4980. 